\title{
A STUDY OF THE PRACTICE OF THE LEARNING ORGANIZATION AND ITS RELATIONSHIP TO PERFORMANCE AMONG KENYAN COMMERCIAL BANKS
}

\author{
Stephen N. M. Nzuve, Edith A. Omolo \\ University of Nairobi, Kenya
}

E-mail: snmnzuve@uonbi.ac.ke

\begin{abstract}
The objective of the study was to investigate the extent of the practice of the learning organization within the Kenyan commercial banks and determine the relationship between the aforementioned practice with organizational performance. The study adopted a descriptive survey design. It was a census survey comprising all the 43 banks licensed to operate in Kenya under the banking Act. The sample frame included all the commercial banks listed in the Central Bank of Kenya website. The 43 banks were further divided into 3 tiers based on profitability for the year 2008 as indicated in the Banking Survey 2009.

Primary data was collected using a structured questionnaire while secondary data regarding organizational performance was obtained from the banking survey 2009. The data collected was analysed using descriptive statistics in terms of frequency and percentage tabulations, cross tabulations and Pearson's correlation coefficient to determine the relationship between the practice of the learning organization and organizational performance.

The study established that most Kenyan commercial banks had to a large extent adopted the following practices adopted by most organizations: development of information systems designed to inform and empower, formative accounting control, learning approach to strategy development, participative policy making, reward flexibility and supportive leadership. The practices least adopted were the ones involved in enabling structures, creating a learning climate and boundary workers as environmental scanners. Findings indicate that there is an inverse relationship between the practice of the learning organization and organizational performance. This would suggest that there are other factors that have to be taken into account to determine and explain this discrepancy, hence the need for further study.

In conclusion, the study established that two thirds of the Kenyan banks had adopted the practices of the learning institution. The study also indicates that there is a tendency for Kenyan commercial banks to focus on certain aspects of the learning organization instead of seeing the whole picture and focusing on the organization as a dynamic entity. Interest in the learning organization has been stimulated by the need to attain sustainable competitive advantage

The researcher recommends that the Kenyan commercial banks should embrace more systematic, definite and concrete steps towards adopting a learning culture, in order to survive the onslaught of competitive forces in the global market. The study suggests further investigation into whether the practices were adopted as part of a systematic strategy to develop the banks as learning organizations or whether they were simply adopted on an ad hoc basis for purposes of expediency and organizational survival.

Key words: learning organization, organizational learning culture, performance indicators, sustainable competitive advantage, global business environment.
\end{abstract}


PROBLEMS

OF MANAGEMENT

IN THE $21^{\text {st }}$ CENTURY

Volume 4, 2012

46

\section{Introduction}

\section{Background}

Interest in the learning organization has been stimulated by the need to attain sustainable competitive advantage in an ever increasingly changing global business environment. The changes within the global business environment include: great advancements in information technology, increased competition as the world becomes a global village, a more informed and demanding global population, an increasingly complex global financial system, the current global recession just to mention a few. In view of this, organizations must redefine the manner in which they conduct business to ensure that they survive. Currently learning is considered to be the only way of obtaining and keeping a competitive edge. Edmonson and Moingenon (1998) state that, "to remain viable in an environment characterized by uncertainty and change, organizations and individuals alike depend upon the ability to learn".

\section{The Learning Organization}

The concept of a learning organization is a recent phenomenon that was first introduced in organizational theory literature, in the late 1980's. The concept was introduced as a response to poor organizational performance. Pedler et al (1989) postulates that it was a way of overcoming, "sluggishness, an excess of bureaucracy and over- control of organizations as straitjackets, frustrating self-development efforts of individual members and failing to capitalize on their potential".

The concept of the learning organization focuses on the whole company perspective on learning and development. It links the development of the potential of each and every member of the organization for development of the company as a whole. It emphasizes the importance of organizational flexibility, responsiveness, adaptability and conscious approach to change (Senge, 1990) and underscores the importance of breaking down outmoded ideas, attitudes and practices before building new skills, structures and values (Pettigrew and Whip, 1991). It is all about a 'systemic' approach that sees everything as being interconnected, rather than a 'systematic' approach that is usually based on a simplistic cause and effect perspective.

The learning organization translates to: "an organization that facilitates the learning of all its members and consciously transforms itself and is about "understanding and mastering the art of cooperate learning... as learning is the key to survival and development for the companies of today" (1997:6).

\section{Organizational Learning Culture}

According to Progress International Ltd (WWW.Change-Management), the aim of organizational learning is to see the value and embrace learning and understand the importance of the development of individual, teams and the overall organization. The said organization argues that, creating a learning culture will empower people in an organization to achieve dramatically improved results compared to the more traditional organizations, as it enables staff to:

- Easily adapt to change

- Actually anticipate change

- Be more responsive to challenges

- Generate the energetic, loyal and goal oriented employees

- Grow through innovation 
Progress International Ltd further states that, a learning culture is to accept a set of attitude, values and practices that support the process of continuous learning within the organization. Training is a key element in the business strategy of an organization dedicated to continuous learning. Through learning, individuals can re-interpret their world and their relationship with it. A true learning culture continuously challenges its own methods and ways of doing things. This ensures continuous improvement and capacity to change.

A leading management scholar, Peter Senge, has identified the following five disciplines of a learning culture that contribute to building a robust organization:

1. Personal mastery - Create an environment that encourages personal and organizational goals to be realized and developed in partnership.

2. Mental models - Knowing persons "internal" picture of their environment will shape their decision and behavior.

3. Shared vision - Build a sense of group commitment by developing shared images of the future.

4. Team learning - Transform conversational and corrective thinking skills, so that a group capacity to reliably develop intelligence and ability is greater than the sum of individual members talents

5. System thinking - Develop the ability to see the "big picture" within an organization and understand how change in one area can affect the whole system.

6. Motivate staff - Training can be a strong motivating factor for your staff, as it helps grow and gain new skills, this will help their performance at work and make them more marketable and employable.

7. Sustainable learning advantage - For an organization to remain productive and competitive in local and global markets, training and lifelong learning should be encouraged across all levels of operation.

Peter Senge, also contends that, the advantages of a learning culture is ịnçẹaṣe in customer satisfaction and profit. The scholar further argues that to achieve a learning culture, organization have to constitute great teams that comprise people who:

- Function together

- Trust and complement each other

- Have common goals that are larger than individual goals

- $\quad$ Produce extraordinary results

- See your organization in a new way

- Commit for the long term

- $\quad$ Self audit

Progress international Ltd suggests the following 10 pre-requisites for an organizational learning culture:

1. Top management commitment

2. Aligning learning culture to business needs

3. Selling clear objectives

4. Personalizing learning

5. Create the right environment for learning

6. Developing contract for learning

7. Removing barriers in learning

8. Building learning culture

9. Encourage experimental mindset

10. Listen to the feedback 
PROBLEMS

OF MANAGEMENT

IN THE $21^{\text {st }}$ CENTURY

Volume 4,2012

\section{Organizational Performance}

Performance is at the core of all activities in any institution. An organization's performance determines its survival in any given economy. Mackie (2008) defines organizational performance as "the effectiveness of the organization in fulfilling its purpose". It would be prudent for organizations to come up with appropriate means or methods for achieving targeted performance levels as well as appropriate performance assessment measures. These have to be designed within the context of a changing global business environment that is increasingly changing the manner in which business is conducted.

In assessing performance, organizations must consider key performance indicators that are usually developed in line with the organization's framework, strategies and objectives. Key performance indicators play a crucial role in determining an organization's level of performance and it can either be financial or non financial. Examples of key performance indicators include measures of customer growth, sales, finances, staff turnover, efficiency ratios etc. Key performance indicators are crucial in evaluating an organization's overall performance.

Improving performance or ensuring sustained levels of great performance, involves developing the right strategies that includes several factors such as developing proper information technology resources, acquiring and retaining the right caliber or quality human capital, developing policies that encourage innovation and experimentation, creating new markets and promoting team work as well as developing appropriate performance measures. The above strategies are central to the concept of the learning organization, hence the increasing focus on addressing the many new challenges that organizations face in the business world today.

\section{The Learning Organization and Organizational Performance}

The learning organization as a concept was developed with a view to improving overall organizational performance. The philosophy underpinning this concept as argued by Garvin (1993) is that learning is an essential ingredient for the survival of organizations. Indeed in his definition of a learning organization, Senge (1990), states that a learning organization is one in which "people continually expand their capacity to create the results they truly desire, where new and expansive patterns of thinking are nurtured, where collective aspiration is set free, and where people are continually learning how to learn together". According to Senge, the notion of the learning organization is all about creating organizational results from individual learning.

Garvin (1993) argues that learning organizations ensure that they learn from experience, develop continuous improvement programmes, use systematic problem solving techniques, and transfer knowledge quickly and efficiently throughout the organization by means of formal training programmes linked to implementation. The key principles of the learning organization as espoused by Miller and Stewart (1999) are aimed at ensuring improved organizational performance through the individuals within the organization. The issue is that learning and business strategy are closely linked, that the organization consciously learns from business opportunities and threats, that individuals, groups and the organization are also learning how to learn, that information systems and technology serve to support learning rather than control it, that there are well defined processes for defining, creating, capturing, sharing and acting on knowledge, and finally that these various systems and dimensions are balanced and managed as a whole. 


\section{The Kenyan Commercial Banking Sector}

The Kenyan banking sector currently comprises over forty banks all under the supervision of the Central Bank of Kenya. The sector has experienced very many radical changes especially in the last eleven years (1998-2009). In the late 1990s and as recently as 2003 , several banks were placed under statutory liquidation due to performance and regulatory issues. It was also during this period that the strike by bank workers had an adverse effect on the performance of the banking sector. This period had also been marked by great technological advancements as banks moved from manual to wholly automated systems with the advent of the automated teller machines, banking technology software and the concept of internet banking. The period had also been marked by increased competition among banks as they sought to provide an ever increasingly informed and demanding customer base with more innovative products. Banks have also been forced to become more creative in income generation especially with the decline in the Treasury bill interest rates, after the year 2003. They have been forced to focus more on non-funded sources of income as well as creating innovative loan products for their customers. The closure of banks towards the end of the 1990s also resulted in more stringent supervision of banks by the Central Bank of Kenya that requires that banking practice be in line with standard banking practice worldwide.

Other more recent changes include the proposed requirement that banks increase their capital base from the current requirement of Ksh.250 million to Ksh.1 billion over a three year period from 2008 to 2011 as provided for in the Kenyan budget for the year 2008. This has resulted in mergers and acquisitions in the banking sector, the largest being the merger of CFC and Stanbic Banks and the takeover of the East African Building Society by Ecobank. The other changes involve the entry of other players into the banking sector with huge amounts of capital such as the entry of Ecobank and more recently United Bank of Africa. There was also the introduction of sharia banking with the entry of banks such as the Gulf African Bank and the First Community Bank.

Other challenges that have arisen include competition from outside the financial sector such as the development of "M-pesa" and the "zap "products introduced by Safaricom and Airtel in the telecommunications sector. M-pesa has especially given banks a run for their money as it has provided a cost effective and efficient means of transferring money and holding accounts that do not involve as complicated and expensive a process as required by the banks. This particular service has opened up the massive potential of the unbanked population of about 17 million people within Kenya (The Banking Survey Kenya 2008).

In addition there are many more investment options currently available to discerning Kenyans, for example the Nairobi Stock Exchange, pension fund schemes and real estate investment to mention but a few.

Banks have been forced to reinvent themselves in order to compete in the increasingly volatile and ever changing environment. The big players in the market namely Kenya Commercial Bank, Barclays Bank and Standard Chartered banks have been forced to revise their strategies to counter the threat by small banks' like Equity, NIC, CFC Stanbic that have risen to become major players in the market. While some banks have flourished and experienced phenomenal growth, others have been unable to compete and have experienced a steady decline in their performance over the years. To establish the reasons for this disparity the study examined how the different banks have evolved and whether those that have succeeded employ key performance indicators that are similar to the attributes of the learning organization as opposed to those that are not success stories. 
PROBLEMS

OF MANAGEMENT

IN THE $21^{\text {st }}$ CENTURY

Volume 4, 2012

\section{The Research Problem}

Case studies undertaken by Richard Karash in the 1980's and early 1990's in the developed world, have shown that the acceptance and establishment of the concept and practices of the learning organization has been crucial in directing organizations down the path of success. This is especially so, given the ever changing global business environment within which organizations operate. The cases studied by Karash that have introduced this concept in their organizational culture with a modicum of success are the Motorola University, Apple Japan and Yacimientos Petroliferos Fiscales (YPF) an oil company in Argentina. Apple Japan managed to grow its market share to $15 \%$ in 1995 from $1 \%$ in 1989. Annual sales soared to US\$ 1.3 billion in 1994 with the sale of 52,000 computers.

In Kenya, however, there is hardly any information on studies that have been done on the concept and practice of the learning organization. Studies done in the past have focused on total quality management (TQM) and teamwork all of which form an important basis for the concept and practice of the learning organization.

This study focuses on the Kenyan banking sector because it is a dynamic sector that has been forced to adjust to the major changes that are taking place both globally and locally in a bid to survive and remain competitively viable organizations. Change implies the adoption and implementation of new practices. It also implies a new way of doing things and a change of perspective. Change therefore demands that the individuals within it learn to accept that change is indeed inevitable and to accept the resultant effects of change. In view of these changes, banks and their employees have had to embrace learning new ways of doing things in order to remain competitively viable institutions. The key to success does not depend on leveraging technology and financial might, but on the quality of human resources that an organization has. The human resource must be trainable and have a capacity for lifelong learning for the organization to succeed. The organization itself must focus on providing an enabling environment for their employees to learn.

Learning new ways of doing things in the changing environment has had a significant impact on the performance of commercial banks in Kenya. While some have experienced phenomenal growth, some have stagnated, and others have experienced significant decline. It would be beneficial to compare the performance of the different commercial banks with regard to key performance indicators. In view of the above, this study sought to investigate the extent to which, the concept and practice of the learning organization has been adopted in the Kenyan commercial banking sector and whether it has had any impact on the performance of the organizations in the banking industry.

\section{Research Objective}

To investigate the extent of the practice of the learning organization within the Kenyan Commercial Banking sector and determine the relationship between the said practices and organizational performance.

\section{Research Questions}

- What is the extent of adoption of the practice of the learning organization within the Kenyan commercial banks?

- How is the relationship between the practice of the learning organization and organizational performance? 


\section{Research Methodology}

\section{Research Design}

This study used the descriptive research design and used the questionnaire technique to collect quantitative data.

\section{Population of the Study}

This study was a census survey comprising all the 43 banks licensed to operate in Kenya under the Banking Act. A census survey involves all the elements of the population and is usually feasible when the population is small and when the elements are quite different. The sample frame included all the commercial banks listed on the Central Bank of Kenya website, www.centralbank.go.ke.

\section{Data Collection}

Primary data for the study was collected using a structured questionnaire. The questionnaire consisted of close ended questions that were divided into two main categories. The first section comprised questions 1-39, that were primarily concerned with determining the practices of the Kenyan commercial banks with regard to the learning organization. The second section comprised questions $40-47$, that tackled the leadership aspect within the respective Kenyan commercial banks. A five point Likert scale was used to measure the research objective.

The respondents were human resource managers in all the banks that were surveyed. The primary data collected was supplemented with secondary data from magazines, journals and other write-ups that focused specifically on the performance of the commercial banks.

\section{Data Analysis}

The raw data collected was edited to ensure that it was accurate, consistent, uniformly entered, complete and arranged to simplify coding and tabulation. Data was coded and entered into the Statistical Package for Social Sciences (SPSS) to allow the information gathered through secondary and primary methods to be converted into a medium for viewing and manipulation.

Descriptive and inferential statistics were used to analyze the data. The researcher used the Pearson Correlation Coefficient to analyze data in order to determine the relationship between the practice of the learning organization and organizational performance. The correlation coefficient was used to reveal the magnitude and direction of the relationship.

\section{Results of Research}

The first specific objective of the study was to determine to what extent Kenya commercial banks reflect the practices of a learning organization. To achieve this, the eleven point diagnostic jigsaw developed by pedlar, Burgoyne and Boydall (1991, 1997), that provides eleven basic practices of a learning organization was used to develop a questionnaire that was intended to identify each of the said practices among the Kenyan commercial banks.

The study found out that most of the Kenyan commercial banks had to a large extent adopted the practice of a learning organization. The practices adopted by the majority were: development of information systems designed to inform and empower, formative accounting and control, learning approach to strategy, participative policy making, reward flexibility and supportive leadership. On the other hand, the least adopted practices were: creating a learning 
PROBLEMS

OF MANAGEMENT

IN THE $21^{\text {st }}$ CENTURY

Volume 4, 2012

climate, boundary workers as environmental scanners and development of enabling structures.

The development of enabling structures is about specifying roles and career flexibility, structured to allow for experimentation, growth and adaptation. According to the findings, the reasons why the aforementioned practices are not highly rated is that there is little room for experimentation in the highly competitive environment in the Kenyan commercial banking sector.

Findings also indicate that some practices are viewed as more important towards improving overall organizational performance, especially in the short term. For example, strategy development is viewed as a critical area for Kenyan commercial banks given the competitive environment within which they operate. Most respondents felt that their leaders supported the development of the different aspects of the learning organization. Findings also indicate that leadership within the commercial banking sector reinforces learning by demonstrating willingly to entertain alternative views. Leaders also realize the importance of spending time on problem identification, knowledge transfer and reflection, and finally engaging in active questioning and listening.

The study divided the banks into three tiers on the basis of their profit performance for the year 2008 as given in the banking survey 2009.

\section{Rating of Kenyan Commercial Banks as Learning Organizations per Tier}

For purposes of the study, banks were divided into three major categories namely Tier I, II and III as given in the peer ranking of banks in the Banking Survey 2009. Tier I banks, rẹprẹsent the banks at the top of the Kenyan commercial banking sector by virtue of key performance indicators namely, profit and balance sheet size. Tier II banks, are those in the middle and Tier III banks are the small banks in the Kenyan commercial banking sector. The scores attained in each sector are given in Tables 1 and 2 below. The mean score per tier is also given.

Table 1. Rating of Tier I banks as learning organizations.

\begin{tabular}{|c|c|c|c|}
\hline $\begin{array}{c}\text { Percentage class } \\
\text { interval (\%) }\end{array}$ & $\begin{array}{c}\text { Mid - Point } \\
(\mathbf{X})\end{array}$ & $\begin{array}{c}\text { Frequency } \\
(\mathbf{F})\end{array}$ & (XF) \\
\hline $1-20$ & 10.5 & 0 & 0 \\
\hline $21-40$ & 30.5 & 1 & 30.5 \\
\hline $41-60$ & 50.5 & 3 & 151.5 \\
\hline $61-80$ & 70.5 & 5 & 352.5 \\
\hline $81-100$ & 90.5 & 1 & 90.5 \\
\hline & & 10 & 625 \\
\hline
\end{tabular}

Of the 10 respondent banks in Tier I none scored between 1\%-20\%, 1 bank scored between $21 \%$ - 40\%, 3 banks scored between $41 \%-60 \%$, 5 scored between $61 \%-80 \%$ and only 1 scored between $81 \%-90 \%$. The average score for the banks in this tier was determined as $62.5 \%(625 / 10)$.

The mean deviation from the mean score of $62.5 \%$ attained by the banks in Tier 1 can thus be determined based on the data provided in Table 2 below. 
Table 2. The scores attained in sectors.

\begin{tabular}{|c|c|c|c|c|}
\hline Class interval & $\begin{array}{c}\text { Mid-Point } \\
(\mathbf{X})\end{array}$ & $\begin{array}{c}\text { Frequency } \\
(\mathbf{F})\end{array}$ & $\mathbf{( X - A )}$ & $\mathbf{F}(\mathbf{X}-\mathrm{A})$ \\
\hline $1-20$ & 10.5 & 0 & -52 & 0 \\
\hline $21-40$ & 30.5 & 1 & -32 & 32 \\
\hline $41-60$ & 50.5 & 3 & -12 & 36 \\
\hline $61-80$ & 70.5 & 5 & 8 & 40 \\
\hline $81-100$ & 90.5 & 1 & 28 & 28 \\
\hline & & 10 & & 136 \\
\hline
\end{tabular}

The mean deviation from the mean score for banks in Tier I is $13.6 \%(136 / 10)$. Tier I banks were better rated as learning organizations as they had taken more concrete steps towards becoming learning organizations. Tier II and III banks interestingly were rated more or less at the same level. Tier III banks scored marginally higher as learning organizations.

The second specific objective of the study was to determine if there was indeed a relationship between the practice of the learning organization and organizational performance.

The key performance indicator used in this particular study was the efficiency ratios based on the performance for the year 2008, of each of the 30 respondent banks as given in the Banking Survey 2009. The efficiency ratio is determined by considering total organizational costs as a proportion of total income. The higher the ratio the less efficient the organization in terms of cost management vis - a - vis income. In the study, the mean efficiency ratio per tier was established and this was compared against the mean rating received by each tier as a learning organization. These figures were then used to determine the relationship between the two variables using the Pearson correlation coefficient.

Tier I banks had a mean efficiency ratio of $56.5 \%$ and rating of $62.5 \%$ as learning organizations. Tier II banks had a mean efficiency ratio $61.93 \%$ and a rating of $59.07 \%$ as learning organizations and Tier III banks had a mean efficiency ratio of $73.58 \%$ against a mean rating of $59.73 \%$ as learning organizations. Using Pearson's correlation coefficient it was determined that the correlation coefficient between the practice of the learning organization and organizational performance was 0.588 . This simply means that there is an inverse relationship between the practice of a learning organization and organizational performance. The higher the score attained as a learning organization the lower the efficiency ratio should be, depicting a more efficient institution.

Based on these findings, Tier I banks conformed to the rule because they had the lowest efficiency ratio score and the highest rating as learning organizations. Interestingly, as per the findings tier II banks scored the lowest as learning organizations yet they had a lower efficiency rating than Tier III banks. This would suggest that there are other factors that have to be taken into account to determine and explain this disparity.

Within any organization, leadership is key in terms of creating a successful institution. The study established that most respondent banks had a very favorable view on the nature of leadership within their institutions. Most respondents believed their leadership were forward thinking and committed to developing their institutions as centers of excellence. 
PROBLEMS

OF MANAGEMENT

IN THE $21^{\text {st }}$ CENTURY

Volume 4, 2012

\section{Conclusion}

The study established that the Kenyan commercial banks had to a large extent practiced the basic tenets of the learning organization. This is in view of the fact that, the mean score for all banks in all the tiers regarding practices of the learning organization was determined as $60.17 \%$. Based on the above findings, there is a need for the Kenyan commercial banks to focus on certain practices of the learning organization first, rather than seeing the bigger picture by focusing on the organization as a dynamic entity before they put their houses in order.

Based on the findings, it would appear like only the ideas that have been tried before are readily adopted, owing to the fact that most institutions avoid the expense of making mistakes. In view of the above, it would seem like currently employee development is not a priority area for Kenyan commercial banks.

\section{Recommendations}

The study recommends that it is necessary for the Kenyan commercial banks to clearly define their strategic objectives and they must also learn to be flexible in view of the changes taking place within the sector. Technological development is another critical area to commercial banks within the Kenyan context. For example, developing information systems that promote and improve bank performance, could greatly enhance efficiency in services provided to the customer.

The study recommends that it is important that all practices be accorded the same level of importance as they all have a substantial impact on organizational performance in the long term. One of the disciplines espoused by Senge (1990) was that of systems thinking. He argued that system thinking is essential for the development of an effective learning organization. It refers to the ability comprehend and address the whole and to examine the interrelationships between the parts.

The study also commends the leadership of these banks for having attained positive approval ratings and would recommend that they focus on giving equal weight and importance to all practices of the learning organization. It is especially important that they focus on those practices within their organization where they have lagged behind, such as intercompany learning and exchange, the development of a learning climate, the creation of enabling structures and improve on those that they have acted upon like internal exchange or team work and self -development opportunities for all.

The performance of an organization is not just about profits and the study therefore recommends that alternative measures for performance enhancement that do not necessarily focus solely on business outcomes be accorded due attention. Learning has become a way of life for world class organizations. The organizations that will survive in the rapidly changing global business environment are those that embrace the learning process and consistently create new knowledge and disseminate it throughout the organization in order to embody it in their technologies, products and services. To compete on the global scale, Kenyan commercial banks must take more systematic, definite and concrete steps towards adopting a learning culture as it is only those companies that embrace change and adapt learning cultures that will survive the onslaught of competitive forces in the global market.

\section{Suggestions for Further Research}

The study established that Kenyan banks to a large extent practiced the basic tenets of the learning organization. The study proposes that a further area for study would be to investigate whether the tenets of the learning organization were adopted as part of systematic strategy to 
Stephen N. M. NZUVE, Edith A. OMOLO. A Study of the Practice of the Learning Organization and its Relationship to Performance among Kenyan Commercial Banks

develop the banks as learning organizations or whether they are simply practices that have been adopted on ad hoc basis for purposes of expediency and organizational survival.

\section{References}

Argyris, C. (1992). On Organizational Learning. Oxford: Blackwell Business.

Argyris, C., Schon, D. A. (1978). Organizational Learning: A Theory in Action Perspective. Needham Heights, MA: Allyn and Bacon.

Bartram, D., Foster, J., Lindley, P. A., Brown, A. J., Nixon, S. (1993). The Learning Climate Questionnaire. Employment Service and Newland Park Associates Ltd.

Cooper, R. D., \& Schindler, S. P. (2006). Business Research Methods, $9^{\text {th }}$ Edition, Tata McGraw-Hill Companies, Inc., New York.

Edmonson, A., Moingeon, B. (1998). From Organizational Learning to The Learning Organization. Management Learning, 29, 5-20.

Garvin, D. (1993). Building a Learning Organization. Harvard Business Review on Knowledge Management. Cambridge, MA: Harvard Business School Press.

Garvin, D. A., Edmondson, A. C., Gino, F. (2007). Is Yours A Learning Organization? Harvard Business Review on Knowledge Management. Cambridge, MA: Harvard Business School Press.

Garratt, B. (1990). Creating a Learning Organization. Hemel Hempstead: Director Books.

Gekonge, C. (2005). Learning Organizations and Organizational Learning. KASNEB Newsline, April - June 2005 Edition.

Honey, P., Mumford, A. (1989). Manual of Learning Opportunities. Maidenhead: Peter Honey.

Karash, R. (2004). Learning Organizations; Where the Learning Begins, wwwpages, MAEB Group.

Mackie, B. (2008). A Summary of International Organizational Performance Management Literature Highlighting Best Practice In Organizational Performance \& It's Management \& Applicability In A Central Government Context. Retrieved 05/05/2012, from http://www.scotland.gov.uk/ Publications/2008/08/25142353/0.

Marsick, V. J., Watkins, K. E. (1999). Facilitating Learning Organizations: Making Learning Count. Brookfield, VT: Gower.

Miller, S. (1999). People Soft Intergration Tools. Mc - Grawhill Companies.

Pedlar, M., Burgoyne, J., Boydell, T. (1989). Towards The Learning Company. Management Education and Development, 20 (1), 1-8.

Pedlar, M., Burgoyne, J., Boydell, T. (1991). The Learning Company: A strategy For Sustainable Development. Maidenhead: McGraw-Hill.

Pedlar, M., Burgoyne, J., Boydell, T. (1997) The Learning Company: A Strategy for Sustainable Development, $2^{\text {nd }}$ Edition. Maidenhead: McGraw-Hill.

Pettigrew, A., Whipp, R. (1991). Managing Change for Competitive Success (ESRC Competitiveness Surveys). Oxford: Blackwell.

Senge, P. (1990). The Fifth Discipline: The Art and Practice of The Learning Organization. London: Century Business, Random House.

Srivastava, U. K., Shenoy, G. V., Sharma, S. C. (1989). Quantitative Techniques for Managerial Decisions 2nd Edition. New Delhi: New Age International (P) Ltd.

Watkins, K. E., Marsick, V. J. (1993). Sculpting the Learning Organization. San Francisco: Jossey-Bass.

Watkins, K. E., Marsick, V. J. (1996). In Action: Creating the Learning Organization. Alexandria, VA: ASTD Press.

Watkins, K. E., Marsick, V. J. (2003). Making Learning Count! Diagnosing the Learning Culture in Organizations. Advances in Developing Human Resources, 5 (2). 
PROBLEMS

OF MANAGEMENT

IN THE $21^{\text {st }}$ CENTURY

Volume 4, 2012

Advised by Ivars Muzis, Riga Teacher Training and Educational Management Academy,

Latvia

Received: May 01, 2012

Accepted: July 12, 2012

Stephen N. M. Nzuve

BSc, MSc, Senior Lecturer, Department of Business Administration, Lower Kabete Campus, University of Nairobi, P. O. Box 30197 - 00100, Nairobi, Kenya.

E-mail: snmnzuve@uonbi.ac.ke

Website: http://archive.uonbi.ac.ke/profiles/?id=97530

Edith A. Omolo

BA, MBA, Compliance Manager, Middle East Bank Kenya Ltd, Nairobi, Kenya.

E-mail: eomolo@mebkenya.com 